\title{
PSYCHOANALYSIS AND EXPLORATION OF THE UNCONSCIOUS
}

\author{
Prof. PhD. Elena CERNOIU \\ Colegiul Național „Constantin Cantacuzino”, Târgoviște \\ și Universitatea Valahia, Târgoviște, Romania. \\ E-mail: elenacernoiu@yahoo.com
}

\begin{abstract}
The psychic is not homogeneous, uniforms, undifferentiated, linear, but it is present in various forms. It has a great functional and existential differentiation and uniformity. It manifests itself in the form of conscious psyche, subconscious and unconscious. The relationship between them, their harmony or conflict, determines the originality of human nature. The unconscious as a form of the psyche constitutes the most controversial level of organization of psychical life. It is stated that psychology stopped placing the notion of conscience in the center of its theoretical and practical preoccupations, making place for the unconscious. The unconscious is not only whatever became automatism, but also what I suppress. Freud explains suppression by a conflict between Superego (which represents the childhood interdictions which became interiorized) and Id, the natural pulsations which we were taught in childhood to blame. Freud urges us, through this, to regain the conscience of what is unconscious. The Superego is a necessary stage in the forming of moral conscience, but it should not be mistaken for the moral conscience itself. The genuine moral conscience does not reduce itself to the Superego. A psychological explanation of the origin of the Superego does not replace the foundation of the moral conscience. Psycho-analysis cannot account for values.
\end{abstract}

Keywords: projective tests; psyche; psycho-analysis; the hypostasis of the psyche (Id, Ego, Superego); sublimation;

\section{INTRODUCTION}

In common language, the conscious means moral consciousness or the capacity to judge our acts and intentions. Consciousness, in Kant's view, means ,the practical reasoning showing man his duty" (Kant, 2007, p. 38). Duty is the necessity of an action out of respect for the law. Only a rational being may act by the simple representation of the law: yet, this rationality is what we call moral. Consciousness is not a judge but a witness. It is the intuition the spirit has about its perceptions and acts.

The famous cogito of Descartes, ,I reason, therefore I am, is nothing more than the statement that I am, without any doubt, an ego, a conscious subject" (Discourse on Method, 1637; Metapyisical Meditations, 1641). Descartes proposed to doubt anything he sees and thinks: As far as I am concerned, I have proposed to improve all my appreciations and not to undervalue them, and I have thought I should commit a big mistake against reason if something already accepted would continue being accepted, even if it had tried to be true or I had tried to estimate it as such (Descartes, 1990, p. 126).

In the second rule of the provisional code, Descartes makes the distinction between intelectual reasoning and the sphere of practical life, where it is advisable to follow a 
dominant opinion: ,my second maxim was to be as firm and steady as possible as far as my actions were concerned and to invariably follow even the most doubtful opinions, once I decided to accept them, as if they were reliable opinions" (Descartes, 1990, p. 126). And observing that this truth cogito ergo sum was so steady and fast, that even the most extravagant assumptions of the sceptics could not undermine, I considered to accept it unscrupulously as a main principle of the philosophy I was looking for. For Descartes, as it can be seen, thinking is identical to conscience. For him, man has a double structure: he is soul, that is conscious thinking, and body, that is a part of strech.

Alain (1868-1951) explains in his own philosophy the Cartesian ideas: „To know, he says, is to know that you know". Otherwise put it, nobody can think without having the conscience that he thinks; what is unconscious does not have anything to do with thinking, it depends on the body. It would be a big mistake ,to think that the unconscious is a kind of alter ego, a kind of evil angel, a diabolical adviser" (Alain, Éléments de philosophie, 1916) J. P Sartre goes along this Cartesian line, too. For him, the object of psychology is a being in a situation. But a being in a situation is a conscientious being. Sartre will ignore the unconscious in the strong sense of the word (in its place he will study the mala fide, but this one is a conscientious attitude). For Descartes, thinking, being essentially conscientious, the notion of unconscious thinking is a contradiction of terms.

Conscience can be defined as everything or nothing. It has sometimes been reduced to a simple psychical function, often called vigilence, and at other times, extended up to its loss into the generality of psycic life, by assimilation with reflexive and critical thinking, with the Ego and personality, with praxis and will ethics (Zlate, 2000, p. 243).

Conscience is already an action, a way to open to the world, to aim at the outside, otherwise put it, conscience is intentionality, as Husserl (1859-1938) characterized this vocation.

The same thing can be said about emotions, feelings. To love or to hate is a way to move towards another feeling. Therefore, the data of my conscience cannot make up an inner life, on the contrary, ,any conscience is at the same time the conscience of something" (Méditations cartésiennes, 1947, p. 28), as Husserl put it. Conscience is intentionality, that is, it is always directed towards something outside myself. We could risk saying that Husserlian conscience is never a state of conscience, but it is always the conscience of a state. Nevertheless, we should add that not every intentionality, any way we project ourselves and direct ourselves to the world is conscious. We will show that clear conscience is only linked to a small number of our attitudes.

Actually, conscience carries out a function of selection. It serves the biological adaptation. It appears every time when some difficulty arises, every time when the automatism of habit is not enough to solve the problem we have. Paul Chauchard (19132003) observes rightfully the fact that losing conscience while sleeping appears as a reaction of unconcern and vice versa, conscience is a reaction of interest but not for everything, only for what can be useful for our body to which we pay attention. Conscience requires, therefore a double conditioning in order to appear: first, the presence of a vital problem which requires a reaction of adaptation, then, a certain difficulty which needs a choice. Conscience appears when the spontaneous activity meets with failure. The more dangerous the situation is, the more intense the conscious will be. Conscience bursts out of contradictions and attempts. It was even said and quite legitimately that „conscience is born out of bad conscience” (S. Freud, Malaise dans la civilisation, 1929, p. 35). 
The idea that ,any conscience means choice” was enlarged upon by Bergson (L'énérgie spirituelle, 1919 , p. 15). He showed that conscience is linked to the present, the real, action. My present task asks for my conscience. I recall, for example, all the memories which are useful to me in order to carry out what I am doing at the moment. Other memories remain unconscious, because they are totally useless for my present activity.

However, conscience is not only selection. It is, as Pierre Janet (1859-1947) showed synthesis. The states of conscience are often pathological or purely states of fatigue when mental synthesis cannot operate. Jean Piaget described conscience as an accompanyiment of actions, differentiating an act conscience ,the previous knowledge of a conscience lot from reflexive conscience an equivalent for what he called 'conscience lot" (Introducere în psihologie, Zlate, 2000, p. 248).

To achieve the main characteristics of the conscience, almost all the psychical processes interfere:

Re-production with science shows the importance of the cognitive processes; the aims express the subject's wishes and aspirations, so, they involve the affective, emotional plan; it's anticipatory, creative character emphasises the presence of creative imagination, its planned character, the presence of thinking. It is only the interaction and interdependence of these that generate the effect of conscience (Zlate, 2000, p. 248).

The reduction of conscience in nature is contradictory through the very existence of conscience, and, if it exists, it means that a supernatural voice calls us.

Moral conscience is oriented towards infinite movement. But, the source of this movement towards the infinite is recognized as inferior to us. Here lies the Christian essence of Kant's morals. What matters to morality (ethics) is the purity of the soul, the sincerity.

So, Kant's supreme moral/ethical law gets the following wording: ,act in such a way as to use the humanity both in your person and in somebody else's person always at the same time, as purpose and not only means" (Flonta \& Keul, 2000, p. 33).

\section{FREUD'S PSYCHIC APPARATUS}

It will be Freud, though, who will give a definition and a scientific foundation to the unconscious. Inspired and influenced by the ideas of the philosophers, psychologists and psycho - pathologists before him, Freud proposed such a conception about the unconscious, that, although it was not he who introduced the respective notion in psychology, his contribution will be considered of cardinal importance. Likewise suggestive is Paul Rincoeur's (1913-2005) remark about Freud's work, ,a monument of our culture”. The main merits of Freud in the investigation of the unconscious are: the discovery of a dynamic conflicting and tense unconscious, correlated to the process of suppression; passing from interpreting the unconscious as nouns denoting mental suppressed deeds to interpreting them as adjectives, as a psychic quality, which means that it is not only memories that have the quality of being unconscious, but also the suppressed mechanisms or whatever starts from the Superego. Freud actually speaks about the existence of three types of the unconscious (the unconscious proper, the Id, a part of the Ego, and the superego, the first representing the suppressed unconscious, the other two, the unsuppressed unconscious. Freud considers the unconscious as being profound, abysmal, not only a psychic automatism, as it appeared with Janet. 


\section{THE DEFINITION OF THE UNCONSCIOUS}

Freud (1856-1939) defined the unconscious in a restrictive and exclusivist manner, considering it only a reservoir of suppressed, restrained, frustrated tendencies. It is the unconscious that explains lapses, pseudoamnesia, failures, dreams.

Other authors define the unconscious in a negative manner, insisting more on its role in all of the psychic life. „According to these authors the unconscious appears as chaos, as irrational, as a whirl of blind pulsations without any kind of organization, with disorganising and inhibiting effects on psychic life, even linking with mental pathology" (Zlate, 2000, p. 267). Contemporary psychology defines the unconscious extensively and positively, as a ,psychical formation which comprises hidden tendencies, emotional conflicts generated by the intimate resorts of personality" (Zlate, 2000, p. 270).

As alter ego, he denies the order imposed by conscience, although this does not mean disorder, but the fact that it brings another order, which is the order of its own subjectivity.

\section{THE NATURE OF THE UNCONSCIOUS}

The unconscious should be interpreted as being predominantly affective. This was justly observed by Jung, who considered that archetypes, condensed and collective images, though instinctive, are close both to sentiment and idea. If the unconscious also comprises elements of cognitive nature, a new question arises: Is the unconscious made up of images or words? „The interaction between image and word verbalization of images, deep visions, suppressed or abysmal, represents the essence of the unconscious" (Zlate, 2000, p. 269).

\section{THE ROLES OF THE UNCONSCIOUS}

Jung thought that the unconscious was even superior to the conscious, because it might contain all the wisdom conferred by the experience of thousands of years. The unconscious ,creates sublime combinations which are greatly superior to the conscious combinations through their finesse and importance" (Zlate, 2000, p. 269).

Lately this opinion has begun to give way. The implication of the unconscious in processing information, problem solving and even creation acts has become an ordinary fact in contemporary psychology. One of the newest psychological trends, transpersonal psychology, gives the unconscious a place and role of first order. The unconscious is the central element of intuition and imagination. It has the following roles: energizing and stimulating the whole psychic life of the individual, facilitating the creation process, thus contributing to the achievement of some spontaneous combinations and recombinations; ensuring the unity of the ego, by being the main depositary of informational programs.

The main merits of Freud in investigating the unconscious are: the discovery of a dynamic, conflicting and tense unconscious, correlative to the process of suppressing; passing from interpreting the unconscious by means of nouns expressing suppressed mental acts to the use of adjectives, as a psychic quality, which means that not only memories have the quality of being unconscious, but also the suppressing mechanisms or whatever goes from Superego; the multiplications which eludes conscience. Freud takes into consideration 3 types of the unconscious: (The self or the unconscious proper; a part of the Ego; the Superego. The first represents the suppressed unconscious, the other two, the unsuppressed unconscious, considering the unconscious as being profound, abysmal, and not only a mere psychical automatism, as it appeared to Janet).

Likewise suggestive is Paul Ricoeur's work, who considered Freud's as being ,a monument of our culture" (Ricoeur, 1965, p. 254). Sigmund Freud is the one who, without 
discovering the unconscious, proposes it as research object for psychology. He introduces the concept of psychic apparatus, conceives a dynamic vision of its components, assembles a technique of examining the unconscious, ultimately changing the finality of psychology itself.

Before 1920, the psychical apparatus was thought by Freud to have three levels: the unconscious, the preconscious and the conscious with the essential role going to the unconscious. The unconscious is a ,spacious antecamera”, while the conscious represents a narrower „room behind it” (Zlate, 2000, p. 86).

Functionally, the unconscious contains pulsations which behave like live beings, while conscience is only a spectator, observing and allowing or not the satisfying of the unconscious' pulsations. Its function goes along a negative line, not in the least positive. It has no role in the socializing or adapting of the individual to the environment solicitations; it only suppresses and sends back to the unconscious those pulsations which try to make an appearance. As the preconscious is concerned, this one - both topographically and functionally - is totally insignificant. It is a kind of transit station, where the tendencies of the unconscious and of conscience come and stop temporarily before going to the opposite structures of each of them.

The unconscious is the place of sexual instincts engraved in the biological somatic structure of the organism. It is then which boil and seethe, it is them whose only reason to exist is to discharge and consume, to diminish tension and to induce pleasure. Freud (18561939) considered that the unconscious works according to the pleasure principle, to which he conceded the statute of fundamental principle of life, while conscience acts according to the reality principle, which presupposes thinking, establishing an action plan, solving problems. As long as there is balance between these instances, man's life is normal, natural. When there is unbalance, force changes, distortions, there appear new interaction models, which are usually of a pathological nature.

Once suppressed, they do not disappear, do not calm down, but act even more viciously against the individual, demanding satisfaction. Suppressed instincts seek their own ways of self satisfying, even against the will of conscience. Thus, they satisfy themselves under the guise of some strange behavioural acts, called by Freud failed acts (inexplicable lapses of proper names, foreign words, reading and writing of errors, blunders etc.), in the form of dream and in more serious cases, in the form of morbid, neurotic states.

Freud is equally interested in finding some methods to bring back balance, to make the psychical apparatus work normally again. This psychotherapeutic method was called psychoanalysis and means bringing back into the subject's conscience the pathogenic elements to dissolve and eliminate the evil caused by the forming of the substituted symptoms.

After 1920, realizing a series of limits of the concept till then, Freud revises the postulates he started from. If, till then, stress was laid on the unconscious and on sexuality, in his work "Self and Ego" (1922) and especially in his last unfinished work „Abriss der Psychoanalyse" (1938), he looks to the superior segments of psychic life, which he analyses in more detail and variety. The psychic apparatus is divided into three structures, called: Self, Ego, Superego or Id, Ego, Superego.

$I d$ is the equivalent to the unconscious from the old classification, the place of instincts, the first source of the psychic energy which has to be consumed, the fundament on which the subject's personality is built. 
Ego is a portion of Id which, under the influence of the outside world, of the environment, suffers a special development, changing from a mere receptacle and protector in relation to stimuli, into an intermediary between Id and the outer world, ,a tree bark", in Freud's words (1980, p. 176).

Superego is a special structure which coagulates itself as a precipitate in the perimeter of the Ego, through which the paternal and maternal influence extends, and through it, the influence of the more general social environment (family, school, race, nation).

The child, through parents, receives social ideals, models. Out of these instances, Freud considers the second to be the most important, thus, the Ego fulfills three great categories of functions: some towards the outer reality (perceives reality, learns, memorises, changes the outer world to his advantage; some towards the Id (controls instincts, decides on satisfying, postponing or suppressing them, tends to obtain pleasure in accordance with the reality principle, because otherwise it would come into conflict with it, but even more than that, Ego has to expel Id, that is to free man from the constraints of the unconscious, a function pre-eminently positive, constructive, humanistic); and lastly, towards Superego (takes into account the moral background which this imposes, the values and traditional ideas of society, in the way they are handed down by parents).

\section{ADLER'S INFERIORITY COMPLEX THEORY (1870-1937)}

For Adler unconscious psychism is determined by the will for power and by the inferiority sentiment, these being compensatory mechanisms, either of some physical deficiencies or some real or presupposed inferiority of Id.

Man possesses an important tendency of superiority, and so his psychical development is due to his struggle which takes place at an unconscious level between a negative tendency and a positive one, the latter being directed towards compensation. Adler, however, makes the same mistake as Freud: he upholds his mechanism as absolute. In reality, both mechanisms may as well be useful for the psychical life of the individual. Adler insists less than Freud on sexuality and more on the affirmation need, the domination over what Nietzche (1844-1900) called will power. The key of neurosis is not usually a sexual difficulty, but the inferiority feeling, especially physical. Neurotic symptoms usually compensate this inferiority.

Adler explains by means of the inferiority complex and compensation what Freud had interpreted starting from suppression. Even sexual behaviour, far from being a fundamental act, may be explained starting from compensation. In an Adlerian perspective, the famous Don Juan behaviour of lord Byron could be explained by the compensation need of his physical infirmity. Stendhal's characters illustrate quite well the inferiority complex theory. They fall in love only when the woman's refusal vexes their self esteem and makes them want to ascertain themselves. We could put it more simply that while Freud tended to explain the manifestations of an ambition by a certain sexual suppression, Adler psychanalyses love searching in its depth the compensation of a failed ambition.

\section{DIFFERENCES OF CHARACTER - JUNG'S CONCEPTION (1825-1961)}

Jung, influenced by Adler, enlarges the sphere of the unconscious considering the libido as the ensemble of dominant instincts, the power instinct included, on the one hand, and, on the other hand as being oriented towards two opposing directions: centripetally and centrifugally, towards the self and towards the world, according to the two orientations of personality-extroversion and introversion. Jung starts from the opposition between Freud and 
Adler. The two perspectives seem both legitimate, though they reveal different temperaments.

For Freud, what counts in the relationship between man and his fellow men is object. Freud ,,sees his subjects in a constant dependence on the important objects of life and in permanent rhythm with them" (Jung, 1952, p. 88). For example, the father and mother play an important role in each person's childhood, later on other persons will take their place by the transfer mechanisms. What comes from the subject is only a blind thirst for pleasure... a vague pleasure which will not enrich itself with qualities unless there are specific objects. While with Freud the subject strangely remains insignificant, with Adler stress is laid on a subject who wants to ensure security and dominate the objects and things, whichever they may be. The Freudian explanation thus proves to be only true for ill people with a certain type of character, while the Adlenian one for the subject with another type of character.

Jung believes there are two different types of people, one of whom attaches himself more to the object than to himself, while the other more to himself than the object. The former is the extrovert, directed towards the exterior, seeking to adapt to the concrete situations and whose destiny actually depends on the objects he finds on his path. When such an individual is touched by neurosis he depends on the Freudian psychanalysis. On the contrary, the introvert, reserved, meditative, hesitant, easily avoids things, always being somehow on the defensive. For this type, the Adlerian concepts apply better.

\section{PSYCHOANALYSIS}

Psycho-analysis is a method of psychological research meant to point out the unconscious preoccupations which we deny admitting to ourselves, otherwise said, which we suppress. ,What we can do better for the subject is, in our role to analyse, to bring to a normal level the psychical processes of his Ego, to change what became unconscious, what was suppressed in the preconscious and thus take it into the Ego" (Renout, 2010, p. 110).

To take the dynamic unconscious to the Ego in order to ensure its command over the Id, this is the objective which drives the analyst, at least in Freud's opinion.

The decisive part of the approach consists of ,,creating new issues out of old conflicts, so that the sick person should behave as he behaved during that time, but using this time all the psychical forces available in order to get to a different solution" (Freud, 1980, p. 366).

The subject is asked to say everything that crosses his mind, even if he considers the respective deeds unimportant for the problem under scrutiny, insignificant, commonplace, minor, stupid, inaccurate: to bring back to mind absolutely everything, not only the good, desirable, pleasant deeds but also the dirty, low, degrading ones. The tormented soul of the patient should be revealed, dissected, analysed without reservation, reticence or restraint, against any critical spirit, any moral precepts. The patient's spontaneous ideas represent for the psycho-analyst ,the ore from which he will extract the precious metal" (Freud, 1980, p. 391).

\section{Transfer}

Without his realizing it, his behaviour towards the analyst unconsciously reproduces his old attitudes. Such a change is called transfer. „The transfer comprises numerous typical phenomena which are individual, unique for each man" (Helmut \& Horst, 1999, p. 96). When it comes to hostility feelings the transfer is called negative. However, transfer may have as an object amiable feelings, it may be positive. 


\section{The Role Of Conflicts}

Freud imagines the psyche as a three-storeyed house. In the middle there is the conscious Ego, which suffers contradictory pressions. From downstairs comes the pressure of the instincts which seek to pass on their exigencies. Freud calls them $I d$. From upstairs comes the pressure of the moral censorship which seeks to suppress the instincts. The ensemble of these moral interdictions is what Freud calls Superego. This Superego itself has an instinctive origin, which needs love and protection.

\section{Oedipus Complex}

The Superego is stronger in boys than in girls. The boy is jealous of his father. $\mathrm{He}$ would like to exclusively enjoy his mother's love. The father is a rival in his reaching this goal. Although he cannot suppress his father, the child identifies with him and interiorizes his words and interdictions. In this sense the Superego is the heir of the Oedipus complex. The Superego is a necessary stage in the formation of the moral conscience but it should not be mistaken for the moral conscience proper. The moral conscience of the adult man, the genuine moral conscience is not equal to the Superego. He who would not have moral conscience but his Superego, would be a childish being focused on childhood interdictions, unable to reach moral autonomy.

\section{The Notion Of Significance}

The Freudian psycho-analysis brings to psychology this essential idea that psychic phenomena, even those in which disorder seems to rule (dreams, the morbid symptoms of neurosis) which at first sight seem absurd, have a hidden finality. While Descartes could not find a ,human significance proper but in the logical processes of thinking and he explained the passions and instincts by means of nervous mechanics laws" (Descartes, 1993, p. 57), Freud thinks that instincts, passions, dreams, the seemingly absurd symptoms of neurosis have a hidden and yet accessible significance.

\section{The Role Of Childhood In The Forming Of Personality}

„The child is man's father" is a statement that receives from psycho-analysis decisive proofs and typical illustrations. The childhood psychical traumas, the first relations parentchild are essential data which have to be discovered, revealed from the unconscious in order to understand the present reactions of the adult subject. In the psyco-analyst view, I am not but what my history made me, I am my past. The psycho-analytical cure aims at freeing me from the burden of this past, helping me to get a clear conscience of it. Once cured, the subjects is no longer its past, yet he has a past.

\section{CONCLUSION}

The psycho-analytical method ended up by imposing itself, renewing the conceptions of psychology. However, we would make a big mistake if we turned this excellent psychological method into a systematic philosophy, that is, if we pretended to explain all the manifestations of human culture by means of it.

Freud sometimes tried to explain all values using psycho-analysis. And so, the moral conscience could be mistaken for the Superego. This tendency to explain values through complexes made Freudians be considered materialists (August Comte-had already said that materialism means "the explanation of the superior through the inferior"). Nevertheless, a psychological explanation of the origin of the Superego does not replace the research of the foundation of moral conscience. Psycho-analysis cannot account for values. It "will not explain what is less human in a man". 


\section{BIBLIOGRAPHY:}

[1] Alain. (1916). Éléments de philosophie. Paris: Folio.

[2] Bergson , H. (1919). L'énérgie spirituelle. Paris: Editura Felix Alcan.

[3] Descartes, R. (1990). Discurs despre metoda de a ne conduce bine rațiunea și a caută adevărul în științe. București: Editura Academiei Române.

[4] Descartes, R. (1993). Meditaţii metafizice. Bucureşti: Editura Crater.

[5] Flonta, M. \& Keul, H.-K. (coord.). (2000). Filozofia practică a lui Kant. Iași: Editura Polirom.

[6] Freud, S. (1929). Malaise dans la civilisation. Viena: Editura Internationaler Psychoanalytischer Verlas.

[7] Freud, S. (1980). Introducere in psihanaliză. Bucureşti: Editura Didactică şi Pedagogică.

[8] Helmut, T. \& Horst, K. (1999). Tratat de psihanaliză contemporană. vol. I. București: Editura Trei.

[9] Husserl, E. (1947). Méditations cartésiennes. Paris: J. VRIN.

[10] Jung, C.G. (1952). Psychologie de l'inconscient. trad. Cahan. Genevè/Librairie De L'université GEORG

[11] Jung, C.G. (2003). Opere complete. Vol. 1. Arhetipurile şi inconştientul colectiv. București: Editura Trei.

[12] Kant, I. (2007). Intemeierea metafizică a moravurilor. București: Editura Humanitas.

[13] Renout, A. (2010). Le sujet. Paris: Editura Odile Jacob.

[14] Ricoeur, P. (1965). De l'intepretation. Paris: Editura Du Seuil.

[15] Zlate, M. (2000). Introducere in psihologie. Iași: Editura Polirom. 